\title{
Urinary biomarkers of diabetic nephropathy
}

This article was published in the following Dove Press journal:

Current Biomarker Findings

22 November 2013

Number of times this article has been viewed

\author{
Swati Mehta' \\ Valerie Jorge Cabrera ${ }^{2}$ \\ Roshni Upputalla ${ }^{2}$ \\ Belinda Jim² \\ 'Department of Medicine, James J \\ Peters VA Medical Center, Bronx, \\ NY, USA; ${ }^{2}$ Division of Nephrology, \\ Department of Medicine, Jacobi \\ Medical Center, Albert Einstein \\ College of Medicine, Bronx, NY, USA
}

Correspondence: Belinda Jim 1400 Pelham Parkway, Building I, Third Floor, Department of Medicine, Jacobi Medical Center, Albert Einstein College of Medicine, Bronx, NY 1046I, USA

$\mathrm{Tel}+\mathrm{I} 7189185762$

$\mathrm{Fax}+17189188364$

Email bun.jim@nbhn.net
Abstract: The fervent search for an early biomarker for diabetic nephropathy is continuing because this entity has become the leading cause of end-stage renal disease in many countries. Novel biomarkers are being described in a high-speed manner. Using urine as a biological source is especially appealing given its ease of collection and its ability to serve as a direct conduit to the site of injury. We begin by briefly discussing the merits and pitfalls of our gold standard of microalbuminuria, and shift quickly to several promising nontraditional protein and messenger (m)RNA biomarkers. The quality of the evidence for using urinary podocyte as a marker will be described. Exploring entire sets of protein in humans in terms of proteomics has been a favorite approach in the last decade because the technology of protein separation and mass spectrometry allows for the unbiased search for new biomarkers. Isolating urinary microRNA may become yet another preferred method because these small, noncoding mRNA that regulate gene expression are particularly stable and apt for biomarker studies. Finally, the latest development is perhaps the study of exosomes, which are nanometer particles derived from the fusion of internal vesicles to the plasma membrane. These particles harbor protein, mRNA, and microRNA that may be isolated for further study. With the advent of newer technologic approaches, we hope that these newly discovered biomarkers will be rigorously tested in large, prospective, clinical trials so they can be implemented in clinical practice.

Keywords: diabetes, predictor, proteinuria, albuminuria, exosomes, proteomics, podocyte

\section{Introduction}

The scourge of diabetes and nephropathy continues to plague our patients and health care system despite advances in the treatment of diabetes. Diabetic nephropathy remains the single largest cause of chronic kidney disease and end-stage renal disease in the US. Prevention is still the most cost-effective strategy. However, in order to offer prevention, we must be able to identify those patients at risk for development and progression of the disease as early as possible. The current clinical marker of microalbuminuria (defined as $<30 \mathrm{mg} / \mathrm{g}$ of albumin measured in the urine) as an early biomarker of diabetic nephropathy is fraught with controversy. Firstly, not all patients with microalbuminuria will progress. Hovind et al showed that although $29 \%$ of patients with type 1 diabetes mellitus (DM) develop microalbuminuria at 18 years of follow-up, only one third of those patients progress to persistent macroalbuminuria; in fact, one third of patients regress spontaneously to normoalbuminuria. ${ }^{1}$ It is also a nonspecific marker, given that urinary albumin levels are upregulated in other kidney diseases (hypertensive nephrosclerosis, tubulointerstitial disease), and other organ diseases (retinopathy and congestive heart failure). ${ }^{2}$ Thus, there is substantial need for a 
biomarker that may enable detection of diabetic nephropathy at an earlier stage with higher accuracy, and one which may further our understanding of the pathophysiology and clinical management of diabetic patients. A biomarker derived from the urine is particularly useful, as it has the advantages of being a simple, noninvasive test and is a direct conduit to the site of injury. In this paper, we review the latest and most promising of urinary biomarkers of diabetic nephropathy. We begin by examining the nontraditional urinary protein and messenger (m)RNA markers, with special emphasis on the podocyte, followed by markers identified via urinary proteomics, microRNAs, and exosomes.

\section{Extracellular matrix markers}

Excessive deposition of extracellular matrix proteins in the mesangium and basement membrane of the glomerulus and the tubulointerstitium is a characteristic finding in diabetic nephropathy. ${ }^{3}$ As such, a selected number of these proteins have been studied as biomarkers for diabetic nephropathy (see Table 1, Figure 1).

Transforming growth factor-beta (TGF- $\beta$ ) has been called the "master regulator" of extracellular matrix production in the diabetic kidney. Both tissue and urinary levels have been shown to be increased in diabetes. ${ }^{4,5}$ It stimulates proteins such as collagen type IV, fibronectin, and laminin. ${ }^{6,7}$ Animal models have shown increased expression of TGF- $\beta$ (urinary and serum) in the hyperglycemic state. ${ }^{8}$ When TGF- $\beta$ levels were measured in patients undergoing elective cardiac catheterization, diabetic patients demonstrated a net renal production of TGF- $\beta$, whereas nondiabetic patients showed a net renal extraction of circulating TGF- $\beta$. As a corollary, urinary levels of TGF- $\beta$ were increased in the diabetic population as compared with nondiabetic controls, emphasizing that TGF- $\beta$ is an important manifestation of diabetic nephropathy. ${ }^{9}$ Urinary TGF- $\beta$ levels were also significantly higher in poorly controlled diabetes as compared with normal or well controlled diabetes; ${ }^{10}$ in fact there was also a positive correlation with glycosylated hemoglobin $\left(\mathrm{HbA}_{1 \mathrm{c}}\right){ }^{10}$ However, when studied prospectively, the prognostic ability of urinary TGF- $\beta$ has been mixed; one study predicted independently the progression of diabetic nephropathy after a 2-year follow-up ${ }^{11}$ whereas another did not. ${ }^{12}$

Connective tissue growth factor (CTGF) is induced by various pathways that include TGF- $\beta$, angiotensin II, signaling mothers against decapentaplegic peptide (Smad), and hypoxia inducible factor. ${ }^{13}$ A relatively large cross-sectional study in type $1 \mathrm{DM}$ patients found that urinary CTGF levels in those with diabetic nephropathy were significantly higher than in patients with microalbuminuria or normoalbuminuria. ${ }^{14}$ Moreover, urinary CTGF levels correlated well with albuminuria and estimated glomerular filtration rate (GFR) in patients with diabetic nephropathy, suggesting its use as a predictive marker. ${ }^{14}$ Subsequently, a prospective trial of type 1 and 2 DM patients for 6 years showed that urinary CTGF levels were also associated with the progression of microalbuminuria, demonstrating its potential as a prognostic biomarker for diabetic nephropathy. ${ }^{15}$ An interventional trial in type $1 \mathrm{DM}$ patients showed that treatment of macroalbuminuric diabetic patients with an angiotensin-converting enzyme inhibitor resulted

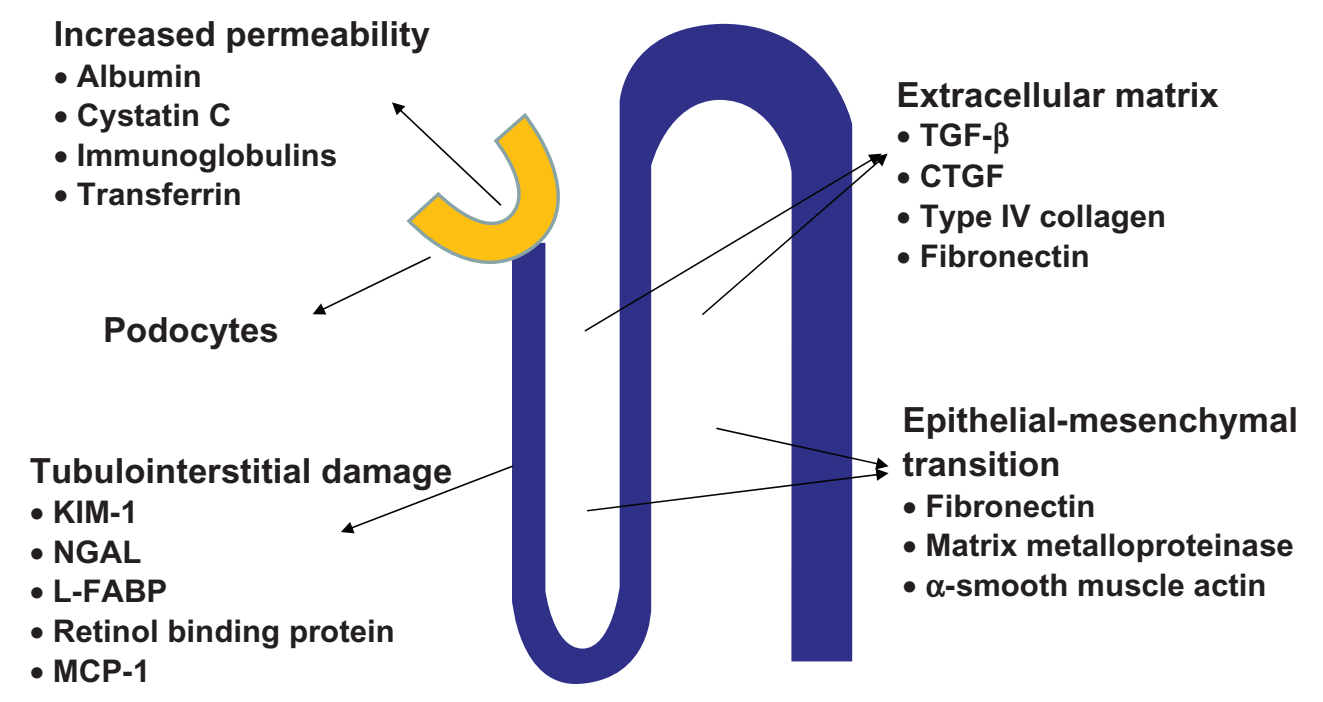

Figure I Origins of urinary biomarkers of diabetic nephropathy.

Abbreviations: NGAL, neutrophil gelatinase-associated lipocalin; KIM-I, kidney injury molecule I; L-FABP, liver-type fatty acid-binding protein; TGF- $\beta$, transforming growth factor-beta; CTGF, connective tissue growth factor; MCP-I, monocyte chemoattractant protein-I. 
Table I Urinary markers of diabetic nephropathy

\begin{tabular}{|c|c|c|c|c|}
\hline References & Biomarker & Properties & Study results & Study specifics \\
\hline$I-3$ & Albumin & $\begin{array}{l}65 \mathrm{kDa} \text {; filtered in glomeruli } \\
\text { followed by tubular reabsorption; } \\
\text { gold standard for diagnosing and } \\
\text { categorizing DN }\end{array}$ & $\begin{array}{l}\text { Significantly higher number of patients with } \\
\text { microalbuminuria develop clinical DN; } \\
\text { significant percentage regress to } \\
\text { normoalbuminuria }\end{array}$ & Prospective \\
\hline 4,5 & TGF- $\beta$ & $\begin{array}{l}25 \mathrm{kDa} \text {; regulates extracellular } \\
\text { matrix production }\end{array}$ & $\begin{array}{l}\text { Urinary levels predict progression of DN } \\
\text { with mixed results }\end{array}$ & Prospective \\
\hline $6-8$ & $\begin{array}{l}\text { Connective tissue } \\
\text { growth factor }\end{array}$ & $\begin{array}{l}36-38 \mathrm{kDa} \text {; fibrogenic cytokine } \\
\text { under regulation by TGF- } \beta\end{array}$ & $\begin{array}{l}\text { Urinary levels were high in diabetic patients } \\
\text { with normoalbuminuria or microalbuminuria } \\
\text { and correlated with albuminuria and eGFR; } \\
\text { treatment with ACEl decreased levels }\end{array}$ & $\begin{array}{l}\text { Cross-sectional/ } \\
\text { interventional }\end{array}$ \\
\hline 9,10 & Type IV collagen & $\begin{array}{l}540 \mathrm{kDa} \text {; component of basement } \\
\text { membrane }\end{array}$ & $\begin{array}{l}\text { Modest correlation with decline in renal } \\
\text { function in DM patients with and without } \\
\text { proteinuria }\end{array}$ & $\begin{array}{l}\text { Prospective/ } \\
\text { cross-sectional }\end{array}$ \\
\hline 11,12 & Fibronectin & $\begin{array}{l}440 \mathrm{kDa} \text {; component of } \\
\text { extracellular matrix in mesangium }\end{array}$ & $\begin{array}{l}\text { Increased urinary levels in type I diabetic } \\
\text { patients with macroalbuminuria; increased } \\
\text { urinary levels in type } 2 \text { diabetic patients with } \\
\text { microalbuminuria and macroalbuminuria }\end{array}$ & Cross-sectional \\
\hline 13 & Cystatin C & $\begin{array}{l}\text { I } 3 \mathrm{kDa} \text {; proteinase inhibitor } \\
\text { produced at constant rate } \\
\text { by all nucleated cells }\end{array}$ & $\begin{array}{l}\text { Freely filtered; not affected by age or muscle } \\
\text { mass, or in proteinuric states in absence } \\
\text { of renal dysfunction }\end{array}$ & Prospective \\
\hline $14-16$ & Transferrin & $\begin{array}{l}76.5 \mathrm{kDa} \text {; more readily filtered } \\
\text { than albumin as it is less anionic }\end{array}$ & $\begin{array}{l}\text { Highly predictive of future development } \\
\text { of microalbuminuria }\end{array}$ & Prospective \\
\hline $15,17-19$ & $\lg G, \lg A, \lg M$ & $\begin{array}{l}\text { Variable molecular weights; } \\
\text { indicate increased glomerular } \\
\text { permeability }\end{array}$ & $\begin{array}{l}\text { Higher urinary IgG levels associated with } \\
\text { development of microalbuminuria; higher } \\
\text { urinary IgM levels associated with renal } \\
\text { and cardiovascular deaths; diabetic patients } \\
\text { have higher urinary } \operatorname{lgG}_{2} \text {, IgA, and IgM levels } \\
\text { compared with healthy controls }\end{array}$ & $\begin{array}{l}\text { Prospective; } \\
\text { cross-sectional }\end{array}$ \\
\hline 20,21 & $\alpha$ I microglobulin & $\begin{array}{l}27 \mathrm{kDa} \text {; indicates proximal } \\
\text { tubular dysfunction }\end{array}$ & $\begin{array}{l}\text { Urinary excretion variably correlated with } \\
\text { albuminuria and glycemic control }\end{array}$ & Prospective \\
\hline 5,22 & $\begin{array}{l}\text { Retinol-binding } \\
\text { protein }\end{array}$ & $\begin{array}{l}21 \mathrm{kDa} \text {; transports retinol } \\
\text { from liver to tissue. }\end{array}$ & $\begin{array}{l}\text { Increased urinary levels in type I DM with or } \\
\text { without microalbuminuria/urinary RBP as an } \\
\text { independent predictor of disease progression }\end{array}$ & Prospective \\
\hline 5,23 & $\begin{array}{l}\text { Monocyte } \\
\text { chemoattractant } \\
\text { protein-I }\end{array}$ & $\begin{array}{l}\text { I } 3 \mathrm{kDa} \text {; chemokine which activates } \\
\text { macrophage and contributes } \\
\text { to tubulointerstitial disease }\end{array}$ & $\begin{array}{l}\text { Urinary levels in DN and advanced } \\
\text { tubulointerstitial lesions; levels predicted } \\
\text { risk of progression of DN }\end{array}$ & $\begin{array}{l}\text { Cross-sectional; } \\
\text { prospective }\end{array}$ \\
\hline 24,25 & $\begin{array}{l}\text { Neutrophil gelatinase- } \\
\text { associated lipocalin }\end{array}$ & $\begin{array}{l}25 \mathrm{kDa} \text {; increased after ischemic } \\
\text { injury }\end{array}$ & $\begin{array}{l}\text { NGAL increases significantly from } \\
\text { normoalbuminuria to microalbuminuria to } \\
\text { macroalbuminuria and significantly reduced } \\
\text { with angiotensin-converting enzyme inhibitor }\end{array}$ & $\begin{array}{l}\text { Prospective/ } \\
\text { cross-sectional }\end{array}$ \\
\hline 26 & $\begin{array}{l}\text { Kidney injury } \\
\text { molecule I }\end{array}$ & $\begin{array}{l}\text { Type I epithelial transmembrane } \\
\text { protein, sensitive marker } \\
\text { of proximal tubular injury }\end{array}$ & $\begin{array}{l}\text { Elevated levels in all diabetic patients with } \\
\text { or without albuminuria; associated with } \\
\text { progression of DN }\end{array}$ & $\begin{array}{l}\text { Prospective/ } \\
\text { cross-sectional }\end{array}$ \\
\hline $27-30$ & $\begin{array}{l}\text { Liver-type fatty acid- } \\
\text { binding protein }\end{array}$ & $\begin{array}{l}14 \mathrm{kDa} \text {, expressed in proximal } \\
\text { tubule cells, increased in ischemia, } \\
\text { hypertension, hyperglycemia }\end{array}$ & $\begin{array}{l}\text { Increased levels predicted development of } \\
\text { microalbuminuria and macroalbuminuria } \\
\text { and mortality in type I DM; levels associated } \\
\text { with increase in albuminuria and ESRD in } \\
\text { type } 2 \text { DM; levels decrease after treatment } \\
\text { with statin }\end{array}$ & $\begin{array}{l}\text { Prospective/ } \\
\text { interventional }\end{array}$ \\
\hline 31 & $\begin{array}{l}\text { Matrix } \\
\text { metalloproteinase- } 9 \text {, } \\
\text { fibronectin, } \alpha \text {-smooth } \\
\text { muscle actin }\end{array}$ & $\begin{array}{l}\text { Urinary mRNA markers of } \\
\text { epithelial-mesenchymal transition }\end{array}$ & $\begin{array}{l}\text { Higher urinary levels in patients with DN } \\
\text { and correlated with severity of disease }\end{array}$ & Cross-sectional \\
\hline $32-35$ & Podocyte & $\begin{array}{l}\text { Urinary podocytes found in DN } \\
\text { and other nephrotic diseases }\end{array}$ & $\begin{array}{l}\text { Increased levels detected in patients } \\
\text { with normoalbuminuria; increased levels } \\
\text { correlated with progression of DN }\end{array}$ & Cross-sectional \\
\hline
\end{tabular}

Abbreviations: DN, diabetic nephropathy; eGFR, estimated glomerular filtration rate; ACEl, angiotensin-converting enzyme inhibitor; DM, diabetes mellitus; ESRD, end-stage renal disease; TGF- $\beta$, transforming growth factor-beta; RBP, retinol binding protein; Ig, immunoglobulin; NGAL, neutrophil gelatinase-associated lipocalin; m, messenger. 
in lowering of their urinary CTGF levels as compared with those who were not treated. ${ }^{16}$

Type IV collagen is the principal component of the glomerular and tubular basement membrane as well as the mesangial matrix. An increased level of type IV collagen fragments in urine may reflect increase turnover of matrix in diabetic nephropathy, ${ }^{17}$ whereas a decrease, on the other hand, may represent a state of low turnover. In a study from Thailand in 30 subjects with type $2 \mathrm{DM}$ and proteinuria, Katavetin et al reported a modest but statistically significant inverse correlation between urinary excretion of type IV collagen and GFR ( $r=-0.39, P=0.04) ;{ }^{18}$ in other words, the higher the urinary collagen IV levels, the more rapid the decline in renal function. Similar results were shown in a Japanese cohort with type $2 \mathrm{DM}$ without overt proteinuria. ${ }^{19}$ This finding was also replicated in a prospective study of type $1 \mathrm{DM}$ patients which showed an association between collagen type IV and a decline in estimated GFR, while albuminuria did not show an association. ${ }^{20}$ However, as most of these studies were done in the Asian population, validation in other ethnic groups would be important.

Fibronectin is a glycoprotein involved in cellular processes such as tissue repair and cellular adhesion. A normal constituent of extracellular matrix in the mesangium, its expression is increased in diabetic nephropathy. ${ }^{21,22}$ In a study by Fagerudd et al, urinary fibronectin levels were found to be increased only in the macroalbuminuria group of type 1 diabetic patients and not in the normoalbuminuria or microalbuminuria groups..$^{23}$ Type $2 \mathrm{DM}$ patients, on the other hand, showed increased levels in the urine of both microalbuminuric and macroalbuminuric patients as compared with age-matched controls. ${ }^{24}$ Kuboki et al studied the relationship between urinary fibronectin degradation products in relation to proteinuria in 64 diabetic patients as compared with eleven healthy volunteers and discovered that not only were these products significantly elevated in the study group, they also correlated with their degree of proteinuria. ${ }^{25}$ Although these initial studies were intriguing, there has not been any recent validation in larger, prospective studies.

\section{Markers of increased glomerular permeability}

Increased glomerular permeability and subsequent passage of large proteins is another common phenomenon in diabetic nephropathy. The etiology is multifaceted and caused by the altered composition of the glomerular basement membrane, impairing both size and charge selectivity, ${ }^{26}$ podocyte dysfunction, and more. ${ }^{26,27}$ We present a number of biomarkers that are derived from this derangement, with a special focus on podocyte markers later on.

Cystatin $\mathrm{C}$ is a cysteine proteinase inhibitor which is produced by all nucleated cells at a constant rate. GFR calculations based on serum cystatin $\mathrm{C}$ have been shown to be more accurate in diabetes. ${ }^{28}$ Urinary cystatin $\mathrm{C}$, on the other hand, is freely filtered and is not affected by age or muscle mass; its levels are also unaffected in proteinuric states without renal tubular damage, thus making it a possible urinary marker of diabetic nephropathy. ${ }^{29}$ A prospective study involving 237 type $2 \mathrm{DM}$ patients followed for 29 months showed that urinary cystatin $\mathrm{C}$ was associated with an annual decline in estimated GFR, especially at the early stages of nephropathy (estimated GFR $\geq 60 \mathrm{~mL} / \mathrm{min} / 1.73 \mathrm{~m}^{2}$ ). Increased levels also correlated with progression of chronic kidney disease stage 3 or greater. ${ }^{30}$ This promising study needs to be validated in a larger cohort.

The transferrin protein is more readily filtered than albumin because it is less anionic and has been studied as an early marker for diabetic nephropathy. In a prospective study of 2 years' duration in normoalbuminuric diabetic patients, increased urinary transferrin excretion was predictive for the development of microalbuminuria (odds ratio 7.04, $P=0.04) .{ }^{31}$ This was subsequently confirmed by a 5 -year follow-up study in type $2 \mathrm{DM}$ patients. ${ }^{32}$ A systematic review found that urinary excretion of transferrin predicts the onset of diabetic nephropathy with high validity, although its prognostic ability for progression of disease is unclear. ${ }^{33}$

There has been interest in the study of urinary immunoglobulins as markers of diabetic nephropathy for decades. In the past, isotypes of immunoglobulins were studied separately, ie, immunoglobulin ( $\mathrm{Ig}) \mathrm{G}$ and its subtypes $\operatorname{IgG}_{1-4}$, $\operatorname{IgA}$, and IgM. Passage of these large proteins was thought to occur via the "large pores" in the glomerular capillaries and to indicate impairment of size selectivity of the glomerular capillary wall. ${ }^{34}$ Occurring before an increase in urinary albumin excretion, an increase in the fractional excretion of $\mathrm{IgG}$ was found to be 2-3 times higher in type 1 DM patients than in control subjects. ${ }^{35}$ In normoalbuminuric type 2 DM patients who were followed for 5 years, higher urinary IgG levels at baseline were associated with development of microalbuminuria. ${ }^{32}$ High urinary IgM levels have been associated with both renal and cardiovascular deaths in type 2 DM patients. ${ }^{36}$ With the advent of a highly sensitive Luminex-based detection method for immunoglobulins in the urine, we are now able to profile all isotypes and subtypes of immunoglobulins simultaneously. Diabetic patients with normoalbuminuria demonstrated significantly higher urinary 
$\operatorname{IgG}_{2}, \operatorname{Ig} \mathrm{A}$, and IgM than healthy volunteers. This increase was further exaggerated in the microalbuminuric group, with $\mathrm{IgG}_{2}$ being the most pronounced. ${ }^{37}$ At this time, prospective studies will be needed to validate whether this new method of immunoglobulin detection is truly predictive of diabetic nephropathy.

\section{Markers of tubulointerstitial damage}

Although diabetic nephropathy has been traditionally thought of as a glomerular disease, studies have shown that the rate of deterioration of function correlates best with the degree of tubulointerstitial fibrosis. ${ }^{38,39}$ Thus, proteins that are upregulated in the tubulointerstitium may serve as valid markers of diabetic nephropathy.

$\alpha 1$ microglobulin is a glycoprotein that is freely filtered by the glomerular filtration barrier in its unbound form (bound forms are not filtered) and is reabsorbed by the proximal tubule where the protein is catabolized. Hence, urinary excretion of unbound $\alpha 1$ microglobulin correlates with proximal tubule dysfunction and can be helpful in early detection of tubular disorders, such as diabetic nephropathy, heavy metal intoxication, and urinary outflow disorders. ${ }^{40}$ In an Asian study from Singapore, $\alpha 1$ microglobulin excretion directly correlated with albuminuria and glycemic control, ${ }^{41}$ although others have not found this association. ${ }^{42}$ Further, lack of international standardization as well as nonspecificity limits its clinical utility as a marker of diabetic nephropathy.

Retinol-binding protein transports retinol (vitamin A alcohol) from the liver to peripheral tissues. A major fraction of retinol-binding protein is bound to transthyretin, but a small unbound fraction $(<10 \%)$ passes freely through the glomerular filtration barrier and is reabsorbed by proximal tubule cells. ${ }^{43,44}$ Increased urinary levels of retinol-binding protein have been found in a pediatric population of type 1 DM patients with and without microalbuminuria, signifying that this marker may be used to detect early tubular damage. ${ }^{45}$ In a recent prospective study that followed type $2 \mathrm{DM}$ patients for an average of 30 months, urinary retinol-binding protein appeared to be an independent predictor of disease progression (risk of dialysis, doubling of serum creatinine or death) after adjusting for confounding factors such as creatinine clearance, proteinuria, and blood pressure. ${ }^{12}$

Monocyte chemoattractant protein-1 is a secreted chemokine that is thought to play an important role in the pathogenesis of tubulointerstitial disease by activating macrophage recruitment in diabetic nephropathy. ${ }^{46}$ Subsequently, urinary monocyte chemoattractant protein-1 levels have been found to be significantly elevated in patients with diabetic nephropathy and advanced tubulointerstitial lesions. ${ }^{46}$ In a prospective study, Titan et al found that urinary monocyte chemoattractant protein-1 predicted the risk of progression of chronic kidney disease in macroalbuminuric diabetic nephropathy, although its role as an early biomarker is still untested. ${ }^{12}$

Neutrophil gelatinase-associated lipocalin (NGAL) is covalently bound to gelatinase from human neutrophils. NGAL is the product of the upregulated gene LCN2 induced after ischemic or nephrotoxic injury. ${ }^{47-49}$ Subsequently, it was investigated as a marker for diabetic nephropathy in a crosssectional study by Nielsen et al in 148 type 1 DM subjects (58 normoalbuminuric, 45 microalbuminuric, 45 macroalbuminuric) which showed that urinary NGAL increased significantly from normoalbuminuria to microalbuminuria to macroalbuminuria $(P<0.05)$; treatment with lisinopril reduced these levels, although the effect was insignificant. ${ }^{50}$ The same authors later showed that elevated levels of urinary NGAL were associated with a greater decline in true GFR as measured by chromium-51 labeled ethylenediamine tetraacetic acid, but these associations were no longer significant after adjustment for confounding factors such as systolic blood pressure and albuminuria. ${ }^{51}$ Fu et al also showed that urinary NGAL levels were elevated in a group of short-term type $2 \mathrm{DM}$ patients (less than 5 years' duration) and that these levels showed a positive correlation with albuminuria and a negative correlation with estimated GFR, as compared with urinary kidney injury molecule 1 (KIM-1, see below). ${ }^{52}$ These studies demonstrate that urinary NGAL may be an early marker of diabetic nephropathy, although prospective studies are lacking.

KIM-1 is a type 1 transmembrane protein present on the apical membrane of the proximal tubule epithelial cell and is upregulated in rodent kidneys after ischemic or toxic injury but not detectable in normal kidney tissue. ${ }^{53}$ In a study reported by Nielsen et al, urinary KIM-1 was elevated in all diabetic patients with or without albuminuria, indicating tubular damage occurring at an early stage. ${ }^{50}$ These authors also reported that urinary KIM-1 was associated with progression of diabetic nephropathy toward end-stage renal disease, but not after adjustment for other known risk factors for progression (albuminuria, blood pressure).$^{51} \mathrm{In}$ contrast with urinary NGAL, Fu et al showed that urinary KIM-1 did not show a correlation with albuminuria or estimated GFR in a group of short-term type $2 \mathrm{DM}$ patients (less than 5 years' duration). ${ }^{52}$ Thus, the prognostic value of KIM-1 for progression of diabetic nephropathy is debatable at this time. 
Liver-type fatty acid-binding protein (L-FABP) is expressed in the proximal tubule cells of the human kidney. Its expression is induced by tubular ischemia, tubular stretch, hyperglycemia, and hypertension. ${ }^{54-57}$ In type 1 DM patients who were followed for 18 years, urinary L-FABP predicted the development of microalbuminuria, macroalbuminuria, and mortality, even after adjusting for confounders such as blood pressure, age, $\mathrm{HbA}_{1 \mathrm{c}}$, and albumin excretion rate. ${ }^{58}$ These findings were validated in a Finnish cohort of type 1 DM patients who were followed for a median of 5.8 years; L-FABP was found to be an independent predictor of progression at all stages of diabetic nephropathy, including normoalbuminuria. ${ }^{59}$ Similarly, in type 2 DM patients, high urinary L-FABP levels are associated with increases in albuminuria, progression to end-stage renal disease, and need for hemodialysis ${ }^{60}$ Treatment with a statin appears to decrease urinary L-FABP levels. ${ }^{61}$ These positive findings have been so compelling that the Ministry of Health has established urinary L-FABP as a new tubular biomarker in Japan.

\section{Markers of epithelial- mesenchymal transition}

Recently, there has been increasing interest in using markers of epithelial-mesenchymal transition (EMT) for identification of diabetic nephropathy. EMT is described as the process of transformation of renal epithelial cells into fibroblasts. ${ }^{62}$ This phenomenon plays a crucial role in the accumulation of extracellular matrix and fibrosis contributing to the development and progression of diabetic nephropathy. ${ }^{63,64}$ Mesenchymal markers for EMT include fibronectin, matrix metalloproteinases (MMPs), and $\alpha$-smooth muscle actin, among others. ${ }^{63,65}$

MMPs promote tubular cell EMT through disruption of the basement membrane and degradation of collagen. ${ }^{66}$ Prior studies measuring MMP levels in 24-hour urine collections have found increased levels of MMP-2 and MMP-9 in patients with type $1 \mathrm{DM}$ and albuminuria. ${ }^{67}$ Another investigation that included type 2 DM patients found increasing levels of MMP-8 and MMP-9 in patients with and without albuminuria, although the highest levels occurred in patients with albuminuria. ${ }^{68}$

Zheng et al recently measured urinary mRNA levels of EMT-associated biomarkers such as $\alpha$-smooth muscle actin, fibronectin, and MMP-9. ${ }^{69}$ Patients with diabetic nephropathy were divided into three groups based on estimated GFR. Higher levels of $\alpha$-smooth muscle actin, fibronectin, and MMP-9 were found in the diabetic nephropathy group compared with controls. Interestingly, increased levels correlated with advanced stages of diabetic nephropathy. These findings make EMT markers promising early biomarkers for diabetic nephropathy, but prospective studies are needed before utilizing this technique.

\section{Podocyte markers}

Perhaps one of the earliest studies that identified an important link between the podocyte and the pathogenesis of diabetic nephropathy came from Pagtalunan et al, who found a progressive reduction in podocyte density (number of cells per volume) in renal biopsies of Pima Indians with overt nephropathy as compared with earlier stages of diabetic nephropathy. ${ }^{70}$ Podocytes, upon injury and detachment, can easily be found in the urine. After discovering urinary podocytes in children and adults with various glomerular diseases, ${ }^{71,72}$ studies in diabetic nephropathy were initiated. The first urinary podocyte study, by Nakamura et al, demonstrated that podocytes were present in patients with microalbuminuria and macroalbuminuria, although the macroalbuminuria group harbored a significantly higher number. ${ }^{73}$ Interestingly, the relationship between podocyturia and albuminuria was poor. Earlier studies used podocalyxin as the marker of choice in identifying podocytes, but their specificity was hampered because this protein is expressed also on endothelial cells, parietal epithelial cells, and a variety of nonrenal cells, such as platelets and hematopoietic stem cells..$^{74-77}$ Markers of the podocyte slit diaphragm, ie, nephrin and podocin, as well as the cytoskeletal protein synaptopodin, are known to be downregulated in diabetic nephropathy, ${ }^{78}$ perhaps signifying shedding of these cells in the urine, rendering them a reasonable urinary marker. The sensitivity of podocyturia, as identified by nephrin for diagnosis, was demonstrated when urinary nephrin (nephrinuria) was found in a substantial number of normoalbuminuric patients, in addition to microalbuminuric and normoalbuminuric patients. ${ }^{79}$ Nephrinuria also appears to portend the development of renal insufficiency, as shown in a Chinese population harboring a significant association between lower estimated GFR and nephrinuria despite being normoalbuminuric. ${ }^{80}$ Using urinary mRNA as yet another method for identifying urinary podocytes, Wang et al found that expression of urinary nephrin, synaptopodin, and podocin was increased in diabetic patients as compared with controls, although only urinary nephrin and synaptopodin correlated with proteinuria and renal function. ${ }^{81}$ Subsequently, urinary mRNA levels of synaptopodin, podocin, and other podocyte-specific molecules were found to increase with progression of diabetic nephropathy, ${ }^{82}$ although this was a cross-sectional study. 
Despite enthusiasm for using podocyturia as markers, its routine clinical use is not yet possible. In order to isolate, identify, and correctly count these cells, we have to make several assumptions. Firstly, we assume that these podocytespecific proteins are preserved upon detachment from the glomerular basement membrane and washed in acidic urine, although this has yet to be confirmed. The process of podocyte identification and counting is also highly observerdependent, ie, the investigator must distinguish podocytes from cellular debris or cells that harbor background staining. The strategy of utilizing urinary mRNA for quantifying podocytes is marred by the vulnerability of mRNA to RNAses and bacteria. ${ }^{83}$ It also requires a larger volume of collection, as much as $100 \mathrm{~mL}$ for an adequate sample, making a random urine collection unfeasible. Thus, before podocyturia can be used routinely, we need an improved method for identifying and quantifying podocytes, a practical technique, standardization of the technique, and importantly, longitudinal studies to define normal and abnormal urinary podocyte numbers. A study by Sakairi et al revealed the ability to generate conditionally immortalized human podocyte cell lines from patients with focal segmental glomerulosclerosis as well as healthy volunteers ${ }^{84}$ This raises the question of a "normal" level of podocyte shedding, a level that may increase with aging. In addition, a comparison of different podocyte markers should also be made to determine which is the most ideal. They must also be compared with the current standard, albuminuria. Our group has demonstrated that nephrinuria, measured by enzyme-linked immunosorbent assay (Exocell Inc, Philadelphia, PA, USA), appears in a majority of normoalbuminuric patients. ${ }^{85}$ When compared with albuminuria, they both showed similar correlations with disease activity. This study signifies the potential to measure nephrinuria in a standardized method that is commercially available as an early biomarker for diabetic nephropathy.

\section{Urinary proteomics}

Proteomics has become a popular method of biomarker discovery in diabetic nephropathy. Proteomics is the assessment of proteomes which comprise all protein and peptide within a particular body compartment. Proteomes are cellspecific and tissue-specific, and change over time. This technique is dependent on the science of protein separation and mass spectrometry; it serves as an unbiased, highthroughput screening of all proteins from a biological source, thus obviating the need for specific antibodies. The different proteomic techniques are provided in a detailed review by Fliser et al. ${ }^{86}$
In a cohort of 70 type $1 \mathrm{DM}$ subjects, with the use of capillary electrophoresis coupled mass spectrometry proteomic methods, a set of 65 biomarkers was able to identify diabetic nephropathy with a sensitivity and specificity of 97\%. ${ }^{87}$ This panel of biomarkers also recognized patients with microalbuminuria who eventually progressed toward overt diabetic nephropathy over a 3-year period. Although not all proteomic biomarkers were sequenced, decreased excretion of certain collagen fragments in patients with diabetes as compared with healthy controls was found. These findings were further validated in a multicenter, case-control study of 148 type 2 DM patients from three European centers with $93.8 \%$ sensitivity and $91.4 \%$ specificity. ${ }^{88}$ Other proteins found to be downregulated in this study were uromodulin, a CD99 antigen fragment, and membrane-associated progesterone receptor component 1 fragment. ${ }^{88}$ These authors also found that urinary collagen fragments of type I and type III may serve as earlier and more specific biomarkers than urinary albumin. ${ }^{88}$

In the largest multicenter study to date, involving 902 participants at ten different centers using capillary electrophoresis coupled mass spectrometry, Maahs et al reported that 131 urinary biomarker candidates were differentially regulated between type 1 and type $2 \mathrm{DM}^{89}$ Specifically, a decrease in urinary level of fragments of collagen $\alpha-1$ (I) and (III) was found in type 2 DM as compared with type 1 DM. This suggests that a disturbance in the physiologic degradation of the extracellular matrix occurs, perhaps due to decreased activity of certain matrix metalloproteases in diabetes..$^{90,91}$ On the other hand, fragments of fibrinogen $\alpha$ and $\beta$ were increased in type $2 \mathrm{DM}$ as compared with type $1 \mathrm{DM}{ }^{89}$ Other proteins sequenced include fragments of $\alpha-1$ antitrypsin, membrane-associated progesterone receptor component 1 , and uromodulin. This panel of biomarkers distinguished type $1 \mathrm{DM}$ from type $2 \mathrm{DM}$ in an independent validation set of normoalbuminuric patients with 88\% (95\% confidence interval $81 \%-94 \%$ ) accuracy and in patients with impaired renal function with $85 \%$ (95\% confidence interval $81 \%-88 \%$ ) accuracy. ${ }^{89}$

In a longitudinal cohort study of type 1 and type $2 \mathrm{DM}$, Zurbig et al reported that a previously validated panel of 273 biomarkers, consisting mostly of collagen fragments, was able to detect subsequent progression to macroalbuminuria in normoalbuminuric subjects (area under the curve 0.93 ). This panel identified progressors in the majority of the cases earlier than the traditional albuminuria (area under the curve 0.67). ${ }^{92}$ In a study that included long-term data, Otu et al discovered a 12-peak molecular signature that predicted $89 \%$ of cases 
of diabetic nephropathy 10 years prior to the development of nephropathy. ${ }^{93}$ However, the actual proteins that constituted this signature were not identified.

Recently, Bhensdadia et al utilized the proteomic approach in a subset of normoalbuminuric patients with type $2 \mathrm{DM}$ from the Veterans Affairs Diabetes Trial to identify new prognostic biomarkers. Of the seven candidate markers that were initially found, only haptoglobin was verified to be the best to predict early renal functional decline. ${ }^{94}$ However, when compared with albuminuria, urinary haptoglobin was equivalent in predicting early decline, although the combination of both albuminuria and urinary haptoglobin improved the ability to predict decline than either biomarker alone.

What has been relatively consistent in these studies is that the collagen synthesis pathway is disrupted in early nephropathy in both type 1 and type 2 diabetes. However, many studies describe only peptide patterns in disease versus control states and thus may be of limited utility. The subsequent steps of protein identification and validation in larger prospective cohorts would be important before these markers can be used in clinical practice.

\section{Urinary microRNAs}

MicroRNAs (miRNAs) are single stranded, noncoding, short RNAs with 21-25 nucleotides that have been found to regulate gene expression through several mechanisms, including translational inhibition, target mRNA degradation and transcriptional inhibition..$^{95-97}$ Their low molecular complexity, preferential tissue expression profile, and ease of collection, along with simple methods of detection and amplification, make miRNAs promising candidates as biomarkers of disease. ${ }^{98}$ In addition, their short sequence of nucleotides provides more stability against degradation by nucleases in the urine. ${ }^{99}$

Five different miRNAs (miR-192, miR-194, miR-204, miR-215, and miR-216) have been identified as being expressed preferentially in the human kidney in comparison with other tissues using a high-density oligonucleotide array. ${ }^{100}$ Additionally, studies of rat kidneys have found differences in the expression profile between the renal cortex and the medulla. Subsequent analysis of the expression profile with real-time polymerase chain reaction showed increased expression of miR-192 and miR-194 in the cortex and increased expression of miR-27b in the medulla. ${ }^{101}$

Aside from their potential as biomarkers, miRNAs also have a role in the development of diabetic nephropathy and, more specifically, in podocyte homeostasis and podocytopathies. ${ }^{96}$ In previous studies, disruption of miRNA biogenesis by selective inactivation of Dicer, an enzyme responsible for the processing of pre-miRNAs into mature miRNAs, in mouse podocytes was shown to be associated with podocyte foot process effacement, apoptosis, mesangial expansion, and glomerulosclerosis. The mutant mice developed proteinuria 4-5 weeks after birth and died weeks later, presumably from renal failure. ${ }^{102}$ Similar findings were seen when using a conditional Dicer allele. ${ }^{103}$

As mentioned earlier, TGF- $\beta$ has an important role in the pathogenesis of diabetic nephropathy. Initially, TGF- $\beta$ was found to induce miR-192 expression in cultured mesangial cells through the repressor protein, Smad-interacting protein, which leads to increased collagen deposition. ${ }^{104}$ However, subsequent studies by Krupa et al and Wang et al showed a decrease in expression of miR-192 in proximal tubular cells $^{105}$ and mesangial cells ${ }^{106}$ after TGF- $\beta$ treatment; in addition, loss of miR-192 expression was associated with increased fibrosis and decreased estimated GFR. This discrepancy may be explained by the fact that the expression profile of miRNAs might differ in the different stages of diabetic nephropathy. For example, miR-192 expression was found to be lower in the renal biopsy tissue of late presenters of diabetic nephropathy as compared with progressors and nonprogressors. ${ }^{105}$

The potential of miRNAs as biomarkers was also explored in a study of 56 patients with chronic kidney disease. This group included 17 patients with a histopathologic diagnosis of diabetic nephrosclerosis, 17 patients with IgA nephropathy, and 22 patients with hypertensive nephrosclerosis. Patients with diabetic nephrosclerosis showed lower levels of miR15 expression as compared with the two other groups. ${ }^{107}$ Interestingly, urinary expression of miR-21 and miR-216a correlated with the decline in renal function and progression to dialysis. ${ }^{107}$ A recent study by Argyropoulos et al analyzed the urinary miRNA profile in type 1 diabetics and identified a spectrum of 27 miRNAs. The authors also found a different miRNA expression profile in the different stages of diabetic nephropathy. However, an association between miR-192 and diabetic nephropathy could not be demonstrated. ${ }^{108}$ Clinical studies of urinary miRNAs are just beginning to be pursued, given the intriguing tissue findings. We eagerly await larger sample sizes from different centers including both type 1 and 2 DM patients before we can conclude whether these biomarkers have true potential.

\section{Exosomes}

A novel approach for biomarker development is to isolate exosomes in the urine. Exosomes are small vesicles, 
usually $40-80 \mathrm{~nm}$ in size, that are derived from the fusion of internal vesicles of multivesicular bodies with the plasma membrane. These vesicles are subsequently released after fusion with the plasma membrane into urine by renal epithelial cells. They may carry protein, mRNA, and miRNA. In a proteomic approach to discover exosomal proteins from Zucker diabetic fatty rats, a model of type $2 \mathrm{DM}$, proteins involved in transport, signaling, and cellular adhesion were identified. They included Xaa-Pro dipeptidase and major urinary protein-1, which were differentially regulated in diabetic urine samples as compared with controls. ${ }^{109}$ In addition to membrane particles, exosomes are known to harbor cytosolic proteins. Wilms tumor 1 (WT1) is a transcription factor that regulates podocyte maturation and is known to be podocyte-specific. Recently, the WT1 protein has been isolated in urinary exosomes of diabetic patients and its levels are significantly higher in patients with proteinuria as compared with those without, although $50 \%$ of patients without proteinuria were also positive for WT1. ${ }^{110}$ Nondiabetic control patients showed an almost absent level of WT1. Furthermore, WT1 levels correlated with proteinuria, albuminuria, serum creatinine, and a decline in estimated GFR, suggesting that this marker be used for early diagnosis and prediction of renal outcome.

At present, exosomal research is limited by its labor-intensive nature and the requirement of expensive equipment for ultracentrifugation to isolate a small amount of material. ${ }^{11,112}$ Newer techniques such as ultrafiltration and precipitation have been reported, and may serve as an alternative approach should ultracentrifugation be unavailable. ${ }^{113}$

\section{Conclusion}

Despite persistent interest in biomarker discovery in diabetic nephropathy over the last several decades, few, if any, have entered clinical practice. This is mostly hampered by the fact that many studies were done in small study populations ( $<100$ patients) of a cross-sectional or short-term prospective nature. Frankly, many of these markers have not been shown to be superior to our gold standard of microalbuminuria. Thus, it is difficult at this time to recommend the use of anyone of these "novel" biomarkers given the above-mentioned limitations. Part of this problem is that if we continue choosing to categorize or define progressive disease by the degree of albuminuria, instead of hard endpoints such as end-stage renal disease, renal replacement therapy, or transplantation, then it might be difficult to find a marker that is superior. Access to banked urine specimens from previous long-term studies in diabetes, such as the Diabetes Control and Complications
Trial, ${ }^{114}$ and its follow-up study, Epidemiology of Diabetes Interventions and Complications, ${ }^{115}$ would be critical. Studies like those harbor more than two decades worth of clinical follow-up data. As exciting as the newer molecular techniques of proteomic and exosomal research may be, they come with increased costs and greater hindrance toward implementation. Therefore, we must address the many scientific and practical concerns in our continued search for an earlier more predictive and prognostic marker of diabetic nephropathy. Perhaps the urgency in finding our "ideal" early marker is tempered by the fact that we still lack an effective intervention. There is no specific treatment for diabetic nephropathy at this time. Inhibition of the renin-angiotensin-aldosterone system is preferentially administered to patients who are diabetic even without nephropathy. Thus, a search for targeted drug therapeutics is perhaps more urgent.

\section{Disclosure}

The authors report no conflicts of interest in this work.

\section{References}

1. Hovind P, Tarnow L, Rossing P, et al. Predictors for the development of microalbuminuria and macroalbuminuria in patients with type 1 diabetes: inception cohort study. BMJ. 2004;328(7448):1105.

2. Haffner SM, Stern MP, Gruber MK, Hazuda HP, Mitchell BD, Patterson JK. Microalbuminuria. Potential marker for increased cardiovascular risk factors in nondiabetic subjects? Arteriosclerosis. 1990;10(5):727-731.

3. Mason RM, Wahab NA. Extracellular matrix metabolism in diabetic nephropathy. J Am Soc Nephrol. 2003;14(5):1358-1373.

4. Hong SW, Isono M, Chen S, Iglesias-De La Cruz MC, Han DC, Ziyadeh FN Increased glomerular and tubular expression of transforming growth factor-beta1, its type II receptor, and activation of the Smad signaling pathway in the db/db mouse. Am J Pathol. 2001;158(5):1653-1663.

5. Tsapenko MV, Nwoko RE, Borland TM, et al. Measurement of urinary TGF-beta 1 in patients with diabetes mellitus and normal controls. Clin Biochem. 2013;46(15):1430-1435.

6. Nakamura T, Miller D, Ruoslahti E, Border WA. Production of extracellular matrix by glomerular epithelial cells is regulated by transforming growth factor-beta 1. Kidney Int. 1992;41(5):1213-1221.

7. Miner JH. Renal basement membrane components. Kidney Int. 1999;56(6):2016-2024.

8. Sharma K, Jin Y, Guo J, Ziyadeh FN. Neutralization of TGF-beta by anti-TGF-beta antibody attenuates kidney hypertrophy and the enhanced extracellular matrix gene expression in STZ-induced diabetic mice. Diabetes. 1996;45(4):522-530.

9. Sharma K, Ziyadeh FN, Alzahabi B, et al. Increased renal production of transforming growth factor-beta1 in patients with type II diabetes. Diabetes. 1997;46(5):854-859.

10. Riojas MA, Villanueva-Vedia RE, Zamilpa R, et al. Prevalence of diabetes mellitus and correlation of urinary transforming growth factorbeta1 with blood hemoglobin A1C in the Atascosa Diabetes Study. Ethn Dis. 2008;18(2 Suppl 2):54-59.

11. Verhave JC, Bouchard J, Goupil R, et al. Clinical value of inflammatory urinary biomarkers in overt diabetic nephropathy: a prospective study. Diabetes Res Clin Pract. July 20, 2013. [Epub ahead of print.]

12. Titan SM, Vieira JM Jr, Dominguez WV, et al. Urinary MCP-1 and RBP: independent predictors of renal outcome in macroalbuminuric diabetic nephropathy. J Diabetes Complications. 2012;26(6): 546-553. 
13. McLennan SV, Abdollahi M, Twigg SM. Connective tissue growth factor, matrix regulation, and diabetic kidney disease. Curr Opin Nephrol Hypertens. 2013;22(1):85-92.

14. Nguyen TQ, Tarnow L, Andersen S, et al. Urinary connective tissue growth factor excretion correlates with clinical markers of renal disease in a large population of type 1 diabetic patients with diabetic nephropathy. Diabetes Care. 2006;29(1):83-88.

15. Tam FW, Riser BL, Meeran K, Rambow J, Pusey CD, Frankel AH. Urinary monocyte chemoattractant protein-1 (MCP-1) and connective tissue growth factor (CCN2) as prognostic markers for progression of diabetic nephropathy. Cytokine. 2009;47(1):37-42.

16. Gilbert RE, Akdeniz A, Weitz S, et al. Urinary connective tissue growth factor excretion in patients with type 1 diabetes and nephropathy. Diabetes Care. 2003;26(9):2632-2636.

17. Yagame M, Suzuki D, Jinde K, et al. Significance of urinary type IV collagen in patients with diabetic nephropathy using a highly sensitive one-step sandwich enzyme immunoassay. J Clin Lab Anal. 1997;11(2): 110-116.

18. Katavetin P, Katavetin P, Susantitaphong P, et al. Urinary type IV collagen excretion predicts subsequent declining renal function in type 2 diabetic patients with proteinuria. Diabetes Res Clin Pract. 2010;89(2): e33-e35.

19. Araki S, Haneda M, Koya D, et al. Association between urinary type IV collagen level and deterioration of renal function in type 2 diabetic patients without overt proteinuria. Diabetes Care. 2010;33(8): 1805-1810.

20. Morita M, Uchigata Y, Hanai K, Ogawa Y, Iwamoto Y. Association of urinary type IV collagen with GFR decline in young patients with type 1 diabetes. Am J Kidney Dis. 2011;58(6):915-920.

21. Makino H, Yamasaki Y, Haramoto T, et al. Ultrastructural changes of extracellular matrices in diabetic nephropathy revealed by high resolution scanning and immunoelectron microscopy. Lab Invest. 1993; 68(1):45-55.

22. Moriya T, Groppoli TJ, Kim Y, Mauer M. Quantitative immunoelectron microscopy of type VI collagen in glomeruli in type I diabetic patients. Kidney Int. 2001;59(1):317-323.

23. Fagerudd JA, Groop PH, Honkanen E, Teppo AM, Gronhagen-Riska C. Urinary excretion of TGF-beta 1, PDGF-BB and fibronectin in insulindependent diabetes mellitus patients. Kidney Int Suppl. 1997;63: S195-S197.

24. Takahashi M. [Increased urinary fibronectin excretion in type II diabetic patients with microalbuminuria]. Nihon Jinzo Gakkai Shi. 1995;37(6): 336-342. Japanese.

25. Kuboki K, Tada H, Shin K, Oshima Y, Isogai S. Relationship between urinary excretion of fibronectin degradation products and proteinuria in diabetic patients, and their suppression after continuous subcutaneous heparin infusion. Diabetes Res Clin Pract. 1993;21(1):61-66.

26. Lewis EJ, Xu X. Abnormal glomerular permeability characteristics in diabetic nephropathy: implications for the therapeutic use of low-molecular weight heparin. Diabetes Care. 2008;31 Suppl 2: S202-S207.

27. Li JJ, Kwak SJ, Jung DS, et al. Podocyte biology in diabetic nephropathy. Kidney Int Suppl. 2007;72(106):S36-S42.

28. Kalansooriya A, Holbrook I, Jennings P, Whiting PH. Serum cystatin C, enzymuria, tubular proteinuria and early renal insult in type 2 diabetes. Br J Biomed Sci. 2007;64(3):121-123.

29. Uchida K, Gotoh A. Measurement of cystatin-C and creatinine in urine. Clin Chim Acta. 2002;323(1-2):121-128.

30. Kim SS, Song SH, Kim IJ, et al. Urinary cystatin C and tubular proteinuria predict progression of diabetic nephropathy. Diabetes Care. 2013;36(3):656-661.

31. Kazumi T, Hozumi T, Ishida Y, et al. Increased urinary transferrin excretion predicts microalbuminuria in patients with type 2 diabetes. Diabetes Care. 1999;22(7):1176-1180.

32. Narita T, Hosoba M, Kakei M, Ito S. Increased urinary excretions of immunoglobulin g, ceruloplasmin, and transferrin predict development of microalbuminuria in patients with type 2 diabetes. Diabetes Care. 2006;29(1):142-144.
33. Hellemons ME, Kerschbaum J, Bakker SJ, et al. Validity of biomarkers predicting onset or progression of nephropathy in patients with type 2 diabetes: a systematic review. Diabet Med. 2012;29(5):567-577.

34. Burne MJ, Osicka TM, Comper WD. Fractional clearance of high molecular weight proteins in conscious rats using a continuous infusion method. Kidney Int. 1999;55(1):261-270.

35. Deckert T, Feldt-Rasmussen B, Djurup R, Deckert M. Glomerular size and charge selectivity in insulin-dependent diabetes mellitus. Kidney Int. 1988;33(1):100-106.

36. Tofik R, Torffvit O, Rippe B, Bakoush O. Urine IgM-excretion as a prognostic marker for progression of type 2 diabetic nephropathy. Diabetes Res Clin Pract. 2012;95(1):139-144.

37. Gohda T, Walker WH, Wolkow P, et al. Elevated urinary excretion of immunoglobulins in nonproteinuric patients with type 1 diabetes. $\mathrm{Am}$ J Physiol Renal Physiol. 2012;303(1):F157-F162.

38. Mauer SM, Steffes MW, Ellis EN, Sutherland DE, Brown DM, Goetz FC. Structural-functional relationships in diabetic nephropathy. $J$ Clin Invest. 1984;74(4):1143-1155.

39. White KE, Bilous RW. Type 2 diabetic patients with nephropathy show structural-functional relationships that are similar to type 1 disease. J Am Soc Nephrol. 2000;11(9):1667-1673.

40. Penders J, Delanghe JR. Alpha 1-microglobulin: clinical laboratory aspects and applications. Clin Chim Acta. 2004;346(2):107-118.

41. Hong CY, Hughes K, Chia KS, Ng V, Ling SL. Urinary alpha1-microglobulin as a marker of nephropathy in type 2 diabetic Asian subjects in Singapore. Diabetes Care. 2003;26(2):338-342.

42. Petrica L, Petrica M, Vlad A, et al. Proximal tubule dysfunction is dissociated from endothelial dysfunction in normoalbuminuric patients with type 2 diabetes mellitus: a cross-sectional study. Nephron Clin Pract. 2011;118(2):c155-c164.

43. Kirsztajn GM, Nishida SK, Silva MS, Ajzen H, Moura LA, Pereira AB. Urinary retinol-binding protein as a prognostic marker in glomerulopathies. Nephron. 2002;90(4):424-431.

44. Bernard AM, Vyskocil AA, Mahieu P, Lauwerys RR. Assessment of urinary retinol-binding protein as an index of proximal tubular injury. Clin Chem. 1987;33(6):775-779.

45. Salem MA, el-Habashy SA, Saeid OM, el-Tawil MM, Tawfik PH. Urinary excretion of n-acetyl-beta-D-glucosaminidase and retinol binding protein as alternative indicators of nephropathy in patients with type 1 diabetes mellitus. Pediatr Diabetes. 2002;3(1):37-41.

46. Wada T, Furuichi K, Sakai N, et al. Up-regulation of monocyte chemoattractant protein-1 in tubulointerstitial lesions of human diabetic nephropathy. Kidney Int. 2000;58(4):1492-1499.

47. Mishra J, Dent C, Tarabishi R, et al. Neutrophil gelatinase-associated lipocalin (NGAL) as a biomarker for acute renal injury after cardiac surgery. Lancet. 2005;365(9466):1231-1238.

48. Mishra J, Ma Q, Prada A, et al. Identification of neutrophil gelatinaseassociated lipocalin as a novel early urinary biomarker for ischemic renal injury. J Am Soc Nephrol. 2003;14(10):2534-2543.

49. Mishra J, Ma Q, Kelly C, et al. Kidney NGAL is a novel early marker of acute injury following transplantation. Pediatr Nephrol. 2006;21(6): 856-863.

50. Nielsen SE, Schjoedt KJ, Astrup AS, et al. Neutrophil gelatinaseassociated lipocalin (NGAL) and kidney injury molecule 1 (KIM1) in patients with diabetic nephropathy: a cross-sectional study and the effects of lisinopril. Diabet Med. 2010;27(10):1144-1150.

51. Nielsen SE, Andersen S, Zdunek D, Hess G, Parving HH, Rossing P. Tubular markers do not predict the decline in glomerular filtration rate in type 1 diabetic patients with overt nephropathy. Kidney Int. 2011;79(10):1113-1118.

52. Fu WJ, Xiong SL, Fang YG, et al. Urinary tubular biomarkers in short-term type 2 diabetes mellitus patients: a cross-sectional study. Endocrine. 2012;41(1):82-88.

53. Ichimura T, Bonventre JV, Bailly V, et al. Kidney injury molecule-1 (KIM-1), a putative epithelial cell adhesion molecule containing a novel immunoglobulin domain, is up-regulated in renal cells after injury. J Biol Chem. 1998;273(7):4135-4142. 
54. Yamamoto T, Noiri E, Ono Y, et al. Renal L-type fatty acid-binding protein in acute ischemic injury. J Am Soc Nephrol. 2007;18(11): 2894-2902.

55. Kamijo-Ikemori A, Sugaya T, Obama A, et al. Liver-type fatty acidbinding protein attenuates renal injury induced by unilateral ureteral obstruction. Am J Pathol. 2006;169(4):1107-1117.

56. Kamijo-Ikemori A, Sugaya T, Sekizuka A, Hirata K, Kimura K. Amelioration of diabetic tubulointerstitial damage in liver-type fatty acid-binding protein transgenic mice. Nephrol Dial Transplant. 2009;24(3):788-800.

57. Ichikawa D, Kamijo-Ikemori A, Sugaya T, et al. Renal liver-type fatty acid binding protein attenuates angiotensin II-induced renal injury. Hypertension. 2012;60(4):973-980.

58. Nielsen SE, Sugaya T, Hovind P, Baba T, Parving HH, Rossing P. Urinary liver-type fatty acid-binding protein predicts progression to nephropathy in type 1 diabetic patients. Diabetes Care. 2010;33(6): 1320-1324.

59. Panduru NM, Forsblom C, Saraheimo M, et al. Urinary liver-type fatty acid-binding protein and progression of diabetic nephropathy in type 1 diabetes. Diabetes Care. 2013;36(7):2077-2083.

60. Kamijo-Ikemori A, Sugaya T, Yasuda T, et al. Clinical significance of urinary liver-type fatty acid-binding protein in diabetic nephropathy of type 2 diabetic patients. Diabetes Care. 2011;34(3):691-696.

61. Nakamura T, Sugaya T, Kawagoe Y, Ueda Y, Osada S, Koide H. Effect of pitavastatin on urinary liver-type fatty acid-binding protein levels in patients with early diabetic nephropathy. Diabetes Care. 2005;28(11): 2728-2732.

62. Lan HY. Tubular epithelial-myofibroblast transdifferentiation mechanisms in proximal tubule cells. Curr Opin Nephrol Hypertens. 2003;12(1):25-29.

63. Zeisberg M, Neilson EG. Biomarkers for epithelial-mesenchymal transitions. J Clin Invest. 2009;119(6):1429-1437.

64. Li J, Qu X, Bertram JF. Endothelial-myofibroblast transition contributes to the early development of diabetic renal interstitial fibrosis in streptozotocininduced diabetic mice. Am J Pathol. 2009;175(4):1380-1388.

65. Djamali A, Reese S, Yracheta J, Oberley T, Hullett D, Becker B. Epithelial-to-mesenchymal transition and oxidative stress in chronic allograft nephropathy. Am J Transplant. 2005;5(3):500-509.

66. Tan TK, Zheng G, Hsu TT, et al. Macrophage matrix metalloproteinase-9 mediates epithelial-mesenchymal transition in vitro in murine renal tubular cells. Am J Pathol. 2010;176(3):1256-1270.

67. Diamant M, Hanemaaijer R, Verheijen JH, Smit JW, Radder JK, Lemkes HH. Elevated matrix metalloproteinase-2 and -9 in urine, but not in serum, are markers of type 1 diabetic nephropathy. Diabet Med 2001;18(5):423-424.

68. van der Zijl NJ, Hanemaaijer R, Tushuizen ME, et al. Urinary matrix metalloproteinase- 8 and -9 activities in type 2 diabetic subjects: a marker of incipient diabetic nephropathy? Clin Biochem. 2010;43(7-8) 635-639.

69. Zheng M, Lv LL, Cao YH, et al. Urinary mRNA markers of epithelial-mesenchymal transition correlate with progression of diabetic nephropathy. Clin Endocrinol (Oxf). 2012;76(5):657-664.

70. Pagtalunan ME, Miller PL, Jumping-Eagle S, et al. Podocyte loss and progressive glomerular injury in type II diabetes. J Clin Invest. 1997;99(2):342-348

71. Hara M, Yanagihara T, Takada T, et al. Urinary excretion of podocytes reflects disease activity in children with glomerulonephritis. Am J Nephrol. 1998;18(1):35-41.

72. Vogelmann SU, Nelson WJ, Myers BD, Lemley KV. Urinary excretion of viable podocytes in health and renal disease. Am J Physiol Renal Physiol. 2003;285(1):F40-F48.

73. Nakamura T, Ushiyama C, Suzuki S, et al. Urinary excretion of podocytes in patients with diabetic nephropathy. Nephrol Dial Transplant. 2000;15(9):1379-1383.

74. Miettinen A, Solin ML, Reivinen J, Juvonen E, Vaisanen R, Holthofer H. Podocalyxin in rat platelets and megakaryocytes. Am J Pathol. 1999;154(3):813-822.
75. Kerjaschki D, Sharkey DJ, Farquhar MG. Identification and characterization of podocalyxin - the major sialoprotein of the renal glomerular epithelial cell. J Cell Biol. 1984;98(4):1591-1596.

76. Achenbach J, Mengel M, Tossidou I, et al. Parietal epithelia cells in the urine as a marker of disease activity in glomerular diseases. Nephrol Dial Transplant. 2008;23(10):3138-3145.

77. Kerosuo L, Juvonen E, Alitalo R, Gylling M, Kerjaschki D, Miettinen A. Podocalyxin in human haematopoietic cells. Br J Haematol. 2004;124(6):809-818.

78. Skoberne A, Konieczny A, Schiffer M. Glomerular epithelial cells in the urine: what has to be done to make them worthwhile? Am J Physiol Renal Physiol. 2009;296(2):F230-F241.

79. Patari A, Forsblom C, Havana M, Taipale H, Groop PH, Holthofer H. Nephrinuria in diabetic nephropathy of type 1 diabetes. Diabetes. 2003;52(12):2969-2974.

80. Ng DP, Tai BC, Tan E, et al. Nephrinuria associates with multiple renal traits in type 2 diabetes. Nephrol Dial Transplant. 2011;26(8):2508-2514.

81. Wang G, Lai FM, Lai KB, Chow KM, Li KT, Szeto CC. Messenger RNA expression of podocyte-associated molecules in the urinary sediment of patients with diabetic nephropathy. Nephron Clin Pract. 2007;106(4):c169-c179.

82. Zheng M, Lv LL, Ni J, et al. Urinary podocyte-associated mRNA profile in various stages of diabetic nephropathy. PLoS One. 2011;6(5):e20431.

83. Camici M. Urinary biomarkers of podocyte injury. Biomark Med. 2008;2(6):613-616.

84. Sakairi T, Abe Y, Kajiyama H, et al. Conditionally immortalized human podocyte cell lines established from urine. Am J Physiol Renal Physiol. 2010;298(3):F557-F567.

85. Jim B, Ghanta M, Qipo A, et al. Dysregulated nephrin in diabetic nephropathy of type 2 diabetes: a cross sectional study. PLoS One. 2012;7(5):e36041.

86. Fliser D, Novak J, Thongboonkerd V, et al. Advances in urinary proteome analysis and biomarker discovery. J Am Soc Nephrol. 2007;18(4): 1057-1071.

87. Rossing K, Mischak H, Dakna M, et al. Urinary proteomics in diabetes and CKD. J Am Soc Nephrol. 2008;19(7):1283-1290.

88. Alkhalaf A, Zurbig P, Bakker SJ, et al. Multicentric validation of proteomic biomarkers in urine specific for diabetic nephropathy. PLoS One. 2010;5(10):e13421.

89. Maahs DM, Siwy J, Argiles A, et al. Urinary collagen fragments are significantly altered in diabetes: a link to pathophysiology. PLoS One. 2010;5(9).

90. Catania JM, Chen G, Parrish AR. Role of matrix metalloproteinases in renal pathophysiologies. Am J Physiol Renal Physiol. 2007;292(3): F905-F911.

91. Kitsiou PV, Tzinia AK, Stetler-Stevenson WG, et al. Glucose-induced changes in integrins and matrix-related functions in cultured human glomerular epithelial cells. Am J Physiol Renal Physiol. 2003;284(4): F671-F679.

92. Zurbig P, Renfrow MB, Schiffer E, et al. Biomarker discovery by CE-MS enables sequence analysis via MS/MS with platform-independent separation. Electrophoresis. 2006;27(11):2111-2125.

93. Otu HH, Can H, Spentzos D, et al. Prediction of diabetic nephropathy using urine proteomic profiling 10 years prior to development of nephropathy. Diabetes Care. 2007;30(3):638-643.

94. Bhensdadia NM, Hunt KJ, Lopes-Virella MF, et al. Urine haptoglobin levels predict early renal functional decline in patients with type 2 diabetes. Kidney Int. 2013;83(6):1136-1143.

95. Kato M, Park JT, Natarajan R. MicroRNAs and the glomerulus. Exp Cell Res. 2012;318(9):993-1000.

96. Alvarez ML, Distefano JK. The role of non-coding RNAs in diabetic nephropathy: potential applications as biomarkers for disease development and progression. Diabetes Res Clin Pract. 2013;99(1): 1-11.

97. Kaikkonen MU, Lam MT, Glass CK. Non-coding RNAs as regulators of gene expression and epigenetics. Cardiovasc Res. 2011;90(3):430-440.

98. Weber JA, Baxter DH, Zhang S, et al. The microRNA spectrum in 12 body fluids. Clin Chem. 2010;56(11):1733-1741. 
99. Hanke M, Hoefig K, Merz H, et al. A robust methodology to study urine microRNA as tumor marker: microRNA-126 and microRNA-182 are related to urinary bladder cancer. Urol Oncol. 2010;28(6):655-661.

100. Sun Y, Koo S, White N, et al. Development of a micro-array to detect human and mouse microRNAs and characterization of expression in human organs. Nucleic Acids Res. 2004;32(22):e188.

101. Tian Z, Greene AS, Pietrusz JL, Matus IR, Liang M. MicroRNA-target pairs in the rat kidney identified by microRNA microarray, proteomic, and bioinformatic analysis. Genome Res. 2008;18(3):404-411.

102. Shi S, Yu L, Chiu C, et al. Podocyte-selective deletion of dicer induces proteinuria and glomerulosclerosis. J Am Soc Nephrol. 2008;19(11): 2159-2169.

103. Harvey SJ, Jarad G, Cunningham J, et al. Podocyte-specific deletion of dicer alters cytoskeletal dynamics and causes glomerular disease. J Am Soc Nephrol. 2008;19(11):2150-2158.

104. Kato M, Natarajan R. MicroRNA circuits in transforming growth factor-beta actions and diabetic nephropathy. Semin Nephrol. 2012;32(3): 253-260.

105. Krupa A, Jenkins R, Luo DD, Lewis A, Phillips A, Fraser D. Loss of microRNA-192 promotes fibrogenesis in diabetic nephropathy. J Am Soc Nephrol. 2010;21(3):438-447.

106. Wang B, Herman-Edelstein M, Koh P, et al. E-cadherin expression is regulated by miR-192/215 by a mechanism that is independent of the profibrotic effects of transforming growth factor-beta. Diabetes. 2010;59(7):1794-1802.

107. Szeto CC, Ching-Ha KB, Ka-Bik L, et al. Micro-RNA expression in the urinary sediment of patients with chronic kidney diseases. Dis Markers. 2012;33(3):137-144.
108. Argyropoulos C, Wang K, McClarty S, et al. Urinary microRNA profiling in the nephropathy of type 1 diabetes. PLoS One. 2013;8(1): e54662.

109. Raimondo F, Corbetta S, Morosi L, et al. Urinary exosomes and diabetic nephropathy: a proteomic approach. Mol Biosyst. 2013;9(6): 1139-1146.

110. Kalani A, Mohan A, Godbole MM, et al. Wilm's tumor-1 protein levels in urinary exosomes from diabetic patients with or without proteinuria. PLoS One. 2013;8(3):e60177.

111. Pisitkun T, Shen RF, Knepper MA. Identification and proteomic profiling of exosomes in human urine. Proc Natl Acad Sci U S A. 2004;101(36):13368-13373.

112. Zhou H, Pisitkun T, Aponte A, et al. Exosomal Fetuin-A identified by proteomics: a novel urinary biomarker for detecting acute kidney injury. Kidney Int. 2006;70(10):1847-1857.

113. Alvarez ML, Khosroheidari M, Kanchi Ravi R, DiStefano JK. Comparison of protein, microRNA, and mRNA yields using different methods of urinary exosome isolation for the discovery of kidney disease biomarkers. Kidney Int. 2012;82(9):1024-1032.

114. The effect of intensive treatment of diabetes on the development and progression of long-term complications in insulin-dependent diabetes mellitus. The Diabetes Control and Complications Trial Research Group. N Engl J Med. 1993;329(14):977-986.

115. Writing Team for the Diabetes Control and Complications Trial/ Epidemiology of Diabetes Interventions and Complications Research Group. Sustained effect of intensive treatment of type 1 diabetes mellitus on development and progression of diabetic nephropathy: the Epidemiology of Diabetes Interventions and Complications (EDIC) study. JAMA. 2003;290(16):2159-2167.
Current Biomarker Findings

\section{Publish your work in this journal}

Current Biomarker Findings is an international, peer-reviewed, open access journal publishing original research, reports, reviews and commentaries on all areas of biomarker research. The manuscript management system is completely online and includes a very quick and fair

\section{Dovepress}

peer-review system. Visit http://www.dovepress.com/testimonials.php to read real quotes from published authors. 